STUDI

FRANCESI

\section{Studi Francesi}

Rivista quadrimestrale fondata da Franco Simone

165 (LV | III) | 2011

LA RAPPRESENTAZIONE DELLA MADRE NELLA

LETTERATURA FRANCESE DEL NOVECENTO a cura di Dario Cecchetti e Michele Mastroianni

\title{
Myriam White-Le Goff, Envoûtante Mélusine - Dietmar Rieger, Guenièvre reine de Logres, dame courtoise, femme adultère
}

Walter Meliga

\section{OpenEdition}

\section{Journals}

\section{Edizione digitale}

URL: http://journals.openedition.org/studifrancesi/4899

DOI: $10.4000 /$ studifrancesi.4899

ISSN: 2421-5856

\section{Editore}

Rosenberg \& Sellier

\section{Edizione cartacea}

Data di pubblicazione: 1 décembre 2011

Paginazione: 618

ISSN: 0039-2944

Notizia bibliografica digitale

Walter Meliga, «Myriam White-Le Goff, Envoûtante Mélusine - Dietmar Rieger, Guenièvre reine de Logres, dame courtoise, femme adultère», Studi Francesi [Online], 165 (LV | III) | 2011, online dal 30 novembre 2015, consultato il 10 janvier 2021. URL: http://journals.openedition.org/studifrancesi/4899 ; DOI: https://doi.org/10.4000/studifrancesi.4899

Questo documento è stato generato automaticamente il 10 janvier 2021.

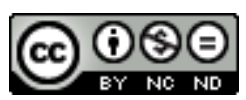

Studi Francesi è distribuita con Licenza Creative Commons Attribuzione - Non commerciale - Non opere derivate 4.0 Internazionale. 


\title{
Myriam White-Le Goff, Envoûtante Mélusine - Dietmar Rieger, Guenièvre reine de Logres, dame courtoise, femme adultère
}

\author{
Walter Meliga
}

\section{NOTIZIA}

MYRIAM WHITE-LE GOFF, Envoûtante Mélusine, Paris, Klincksieck, 2008 («Les grandes figures du Moyen Âge», 1), pp. 234.

DIETMAR RIEGER, Guenièvre reine de Logres, dame courtoise, femme adultère, Paris, Klincksieck, 2009 («Les grandes figures du Moyen Âge», 2), pp. 284.

Come si afferma nel sito web della casa editrice, l'intento della collana (di cui i volumi qui citati rappresentano le prime due uscite) è quello di presentare a un pubblico colto, ma non specialista, aspetti importanti della letteratura e della cultura del Medioevo, assai meno noti rispetto alla storia, che - soprattutto in Francia - beneficia di un ben più forte appeal. Per ottenere lo scopo, è necessario «faire un peu peau neuve en présentant des ouvrages sortant du cadre strict de l'érudition universitaire et de l'écriture académique», che invece sono dominanti in quegli ambiti: la strada scelta è quella di tracciare dei profili di grandi personaggi medievali (qui si tratta di due celeberrime figure femminili, centrali all'interno di leggende di lunga durata: Melusina e Ginevra) e, attraverso di essi, del tempo e della cultura che li sostiene. L'intenzione è apprezzabile e anche il risultato raggiunto: le figure di Melusina e Ginevra sono osservate nel loro sviluppo storico-culturale e letterario, senza trascurare le «riscritture» moderne e contemporanee, che in definitiva sono quelle note al pubblico al quale la collana si indirizza. Alcuni aspetti potrebbero essere migliorati, nella direzione appunto di un'efficace divulgazione: l'apparato iconografico (peraltro 
presente) potrebbe essere messo maggiormente a frutto, anziché ridurlo per lo più a contorno dello scritto; i testi dovrebbero essere più presenti e, benché tradotti, anche nella lingua originale (questa esigenza è particolarmente poco sentita in Francia); la bibliografia, proprio perché «choisie», dovrebbe essere meglio organizzata e brevemente commentata. Invece, le miniaturine in alto e in basso nelle pagine - di gusto rétro, più che medievale - possono essere tranquillamente abbandonate. 